$10 \mid 2006$

Varia

\title{
Avallon (Yonne), note sur l'effondrement du petit surplomb du rempart, au chevet de la collégiale Saint-Lazare
}

Virginie Jolly

\section{(2) OpenEdition}

1 Journals

\section{Édition électronique}

URL : https://journals.openedition.org/cem/167

DOI : $10.4000 /$ cem. 167

ISSN : 1954-3093

Éditeur

Centre d'études médiévales Saint-Germain d'Auxerre

Édition imprimée

Date de publication : 15 août 2006

ISSN : 1623-5770

Référence électronique

Virginie Jolly, «Avallon (Yonne), note sur l'effondrement du petit surplomb du rempart, au chevet de la collégiale Saint-Lazare », Bulletin du centre d'études médiévales d'Auxerre | BUCEMA [En ligne], 10 | 2006, mis en ligne le 08 septembre 2006, consulté le 22 septembre 2022. URL : http:// journals.openedition.org/cem/167; DOI : https://doi.org/10.4000/cem.167

Ce document a été généré automatiquement le 22 septembre 2022.

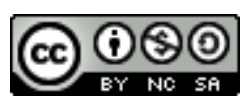

Creative Commons - Attribution - Pas d'Utilisation Commerciale - Partage dans les Mêmes Conditions 4.0 International - CC BY-NC-SA 4.0

https://creativecommons.org/licenses/by-nc-sa/4.0/ 


\title{
Avallon (Yonne), note sur l'effondrement du petit surplomb du rempart, au chevet de la collégiale Saint-Lazare
}

\author{
Virginie Jolly
}

1 Suite à l'effondrement d'un élément de l'enceinte urbaine durant l'hiver 2004, une intervention a été souhaitée conjointement par le Service Régional de l'Archéologie de Dijon (DRAC Bourgogne) et la Municipalité d'Avallon (Yonne). La zone concernée, située à l'est de la ville médiévale, sur le rempart, est en contact direct avec l'esplanade du chevet de la collégiale Saint-Lazare. La configuration escarpée et dangereuse du terrain -instabilité du sol en partie haute et effritement du mur- a limité la marge d'action.

D'après les archives, certaines parties du rempart datent de la fin du xIV $^{e}$ ou du début $\mathrm{du} \mathrm{Xv}^{\mathrm{e}}$ siècle. Les nombreuses modifications qui y ont été apportées ne sont pas toutes datées, et nous manquons encore d'informations sur l'état de conservation de l'enceinte actuelle. Pour toutes ces raisons, il pouvait s'avérer utile de faire une série d'observations sur la partie rendue visible suite à l'effondrement d'un balcon surplombant le rempart.

Les observations

3 La zone d'éboulement est d'environ 4,75 $\mathrm{m}$ de long par 1,50 à $2 \mathrm{~m}$ de haut et $0,75 \mathrm{~m}$ de profondeur. La maçonnerie observée en périphérie de l'éboulement, surtout au nord, mesure $40 \mathrm{~cm}$ d'épaisseur et se divise en deux parties distinctes: d'une part le parement, d'environ 20 à $25 \mathrm{~cm}$ d'épaisseur, puis le blocage, sis entre le parement et le terrain sur lequel est édifiée la collégiale Saint-Lazare. Le mur en petit appareil est constitué d'une majorité de blocs de tout-venant calcaire (dont des calcaires coquillés), liés par un mortier de chaux très sableux, et pulvérulent. Quelques rares blocs de granite rose sont encore en place dans le blocage du mur. D'autres blocs de calcaire, de tailles plus importantes (de $35 \mathrm{~cm}$ à $1 \mathrm{~m}$ de long), et présentant des éléments de décors sculptés ont été trouvés en place dans le blocage, ou dans les éboulements au pied du 
rempart. Autour de la zone observée le rempart est en moyen appareil de granite rose lié par un mortier de chaux pulvérulent. Par conséquent, les deux maçonneries sont différentes, n'employant ni les mêmes matériaux, ni les mêmes liants. De part et d'autre de l'éboulement, le garde-corps de $75 \mathrm{~cm}$ centimètres de haut a été refait au XIX ou au $\mathrm{Xx}^{\mathrm{e}}$ siècle. La distance entre le bas du rempart et le haut de ce muret est d'environ $8 \mathrm{~m}$, alors que le point le plus bas de la zone éboulée n'est qu'à $6 \mathrm{~m}$.

Les éléments en remplois

4 Une série de blocs de calcaire inclus à la maçonnerie du balcon effondré ont attiré mon attention. Sur les quatre blocs utilisés en remplois, un seul est encore en place, dans le blocage. Il mesure $30 \mathrm{~cm}$ de large, $35 \mathrm{~cm}$ de long et $16 \mathrm{~cm}$ d'épaisseur. Seule l'une des faces présente un décor de corniche: un quart-de-rond encadré de deux réglets, et surmonté d'un motif géométrique de U renversés, longs et à l'extrémité desquels s'intercalent des losanges. Ce bloc présente des traces de bretture. Les trois autres blocs étudiés sont extraits de la même maçonnerie, mais sont tous descellés et entreposés en bas du rempart. Le premier, de grandes dimensions, est juste équarri sur deux pans. Les deux faces portent des traces de bretture, et le chant est sculpté d'une moulure en doucine. Le second, plus long que le précédent comporte des traces de bretture sur plusieurs pans, mais aussi des marques laissées par un pic, sur la face inférieure. La mouluration, plus complexe que les deux précédentes, porte des traces de gouges à dents et d'un badigeon blanc. La moulure paraît identique à celle qui ceint la collégiale Saint-Lazare au niveau de son premier étage. Le troisième bloc est celui qui présente le plus d'éléments de décors sculptés. Ces dimensions sont les plus grandes. Il est équarri et ne présente que quelques rares traces de bretture. Il est sculpté sur deux pans. L'une des faces est ornée d'une série de quatre cannelures à arêtes vives. Le décor sculpté sur le chant du bloc est constitué d'un entrelacs circulaire et régulier au milieu duquel ont été détourées au moins six fleurs (de type marguerites) comprenant une ou deux rangées de pétales. Il est difficile de dater ou d'identifier la provenance de ces blocs, car seul l'un d'entre eux présente un motif déjà observé sur la collégiale Saint-Lazare.

5 Les données disponibles ne permettent pas d'affiner la chronologie de ce mur. Toutefois, nous savons que ce balcon était postérieur au xvI ${ }^{\mathrm{e}}$ siècle, et qu'il n'était pas un élément original de l'enceinte urbaine. D'après la stratigraphie et la céramique que nous possédons, les remblais dateraient approximativement du XVII et du XIX siècle et le plus récent serait directement lié à une réfection du balcon panoramique.

Il serait utile d'approfondir la connaissance des parties les plus anciennes de ce rempart ( $\mathrm{XIV}^{\mathrm{e}}-\mathrm{XV}^{\mathrm{e}}$ siècle) avant que ce dernier ne subisse le même sort que le balcon, et en vue de mettre en valeur le patrimoine de cette cité. Une étude globale est en projet en concertation avec la municipalité d'Avallon. 


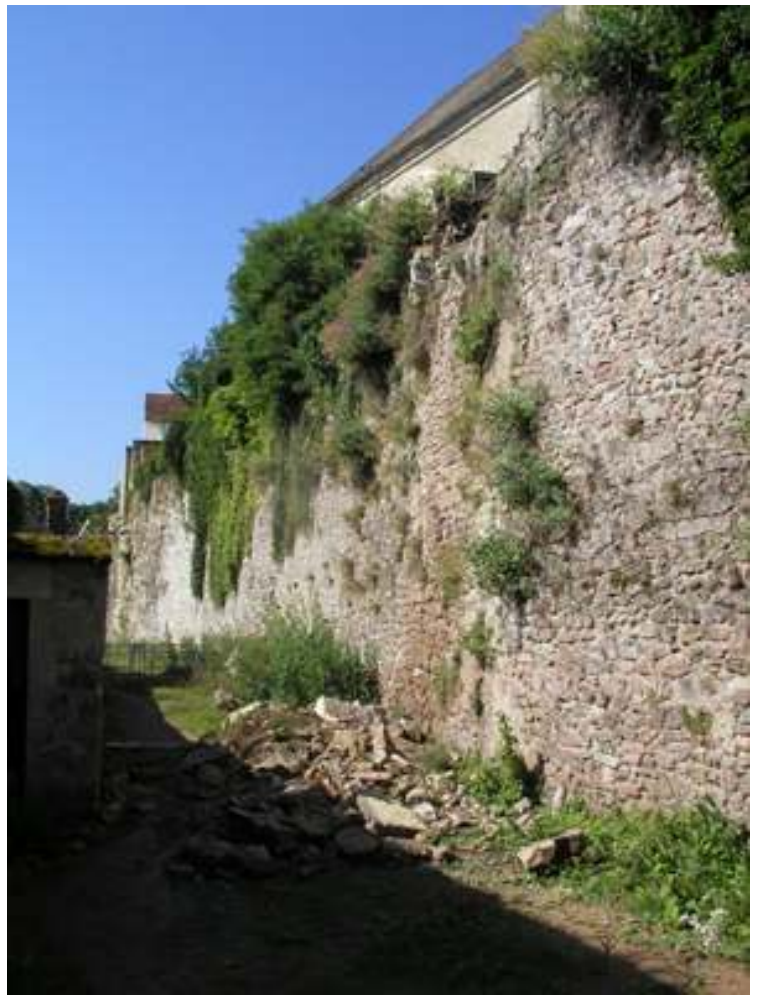

INDEX

Index géographique : France/Avallon

Mots-clés : collégiale, Saint-Lazare d'Avallon, Lazare (saint), rempart 